\title{
微卫星标记分析罗非鱼群体的遗传潜力
}

杨弘 ${ }^{1}$, 李大宇 ${ }^{1}$, 曹祥 ${ }^{1,2}$, 邹芝英 ${ }^{1}$, 肖炜 ${ }^{1}$, 祝璟琳 ${ }^{1}$

1. 中国水产科学研究院淡水渔业研究中心, 农业部淡水鱼类遗传育种与养殖生物学重点开放实验室, 无锡 214081;

2. 南京农业大学无锡渔业学院, 无锡 214081

摘要: 利用 25 个微卫星标记，对奥利亚罗非鱼 2 个群体 [“夏奥 1 号”(ZA)、广西群体(GA)]和尼罗罗非鱼 4 个群 体 $[$ 埃及品系 $(\mathrm{ZN}) 、 88$ 品系 $(\mathrm{XN})$ 、广西群体 $(\mathrm{GN})$ 、美国品系 $(\mathrm{MN})$ ] 进行检测。共检测到 7775 个扩增片段, 长度 在 100 400 bp; 等位基因数 3 8 个不等，共计 143 个等位基因; 平均每个基因座扩增得到 5.72 个等位基因。各 群体平均观测杂合度 $\left(\overline{H_{o}}\right)$ 在 $0.7253 \sim 0.8160$ 之间, 平均期望杂合度 $\left(\overline{H_{e}}\right)$ 在 $0.5146 \sim 0.6834$ 之间, 平均多态信息含 量 $(\overline{P I C})$ 在 $0.4212 \sim 0.6105$ 之间, 平均有效等位基因数 $(\overline{A e})$ 在 $2.20 \sim 3.23$ 之间。 $\mathrm{ZA}$ 与 $\mathrm{GA}$ 遗传相似系数最高 (0.9130), ZA 与 ZN 遗传相似系数最低(0.4352)。总的说来, 4 个尼罗罗非鱼群体的遗传潜力较高, 2 个奥利亚罗 非鱼群体的遗传潜力适中。

关键词：遗传潜力；奥利亚罗非鱼；尼罗罗非鱼；微卫星；遗传多样性

\section{Genetic potential analysis of six Tilapia populations by microsatellite DNA markers}

\author{
YANG Hong $^{1}$, LI Da-Yu ${ }^{1}$, CAO Xiang ${ }^{1,2}$, ZOU Zhi-Ying ${ }^{1}$, XIAO Wei ${ }^{1}$, ZHU Jing-Lin ${ }^{1}$ \\ 1. Key Laboratory of Genetic Breeding and Aquaculture Biology, Ministry of Agriculture, Freshwater Fisheries Research Center, Chinese \\ Academy of Fishery Sciences, Wuxi 214081, China; \\ 2. Wuxi Fisheries College, Nanjing Agricultural University, Wuxi 214081, China
}

\begin{abstract}
Twenty five microsatellite loci were used to analyze two blue tilapia populations ["Xia'ao 1" (ZA), Guangxi population] and four nile tilapia populations [Egypt strain (ZN), 88 strain (XN), Guangxi population (GN), American strain $(\mathrm{MN})$ ]. A total of 7775 fragments ranging from $100 \mathrm{bp}$ to $400 \mathrm{bp}$ in length were obtained. Three to eight alleles were amplified in 25 loci and 143 alleles in all the six populations. The average number of alleles in each locus was 5.72. The average values of observed heterozygosity $\left(\overline{H_{o}}\right)$ ranged from 0.7253 to 0.8160 , the average expected heterozygosity $\left(\overline{H_{e}}\right)$ ranged from 0.5146 to 0.6834 , the average polymorphic information content $(\overline{P I C})$ ranged from 0.4212 to 0.6105 , and the number of average effective alleles $(\overline{A e})$ ranged from 2.20 to 3.23. The highest genetic similarity index was 0.9130 (between ZA and GA); and the lowest was 0.4352 (between $\mathrm{ZA}$ and $\mathrm{ZN}$ ). The results showed that the four nile tilapia populations contained a high level of genetic potential, and the two blue tilapia populations were moderate.
\end{abstract}

Keywords: genetic potential; O. Aureus; O. niloticus; microsatellite; genetic diversity

收稿日期: 2010-08-31; 修回日期: 2011-01-18

基金项目: 国家科技支撑计划专题(编号：2006BAD01A1202), 2007 年公益性行业(农业)科研专项(编号：3-49), 现代农业产业技术体系建设专 项资金(编号：nycytx-48), 中央级公益性科研院所基本科研业务费专项资金(编号：2007JBFA02)和农业部水生动物遗传育种和养殖 生物学重点开放实验室开放基金课题(编号：BM2007-13)资助

作者简介: 杨弘, 研究员, 研究方向：鱼类遗传育种和生物技术。Tel: 0510-85550252; E-mail: yangh@ffrc.cn 
罗非鱼(Tilapias)隶属于鲇形目(Perciforms)、鲈 形亚目(Percoidei)、丽鱼科(Cichlidae)的热带性鱼类, 原产于非洲, 是联合国粮农组织向全世界推广的养 殖对象, 现已成为世界性的主要养殖鱼类之一。上 世纪 50 年代我国首次从越南引进莫桑比克罗非鱼 进行养殖, 此后先后引入尼罗罗非鱼(Oreochromis niloticus)、奥利亚罗非鱼(Oreochromis aureus)等种类 罗非鱼 ${ }^{[1]}$, 在我国南方大部分地区进行推广养殖, 取得了一定的经济效益和社会效益。到 2008 年底, 我国罗非鱼产量已经占全球罗非鱼总产量的一半, 其出口量高居世界第一位 ${ }^{[2]}$ 。罗非鱼众多品种中尼 罗罗非鱼 $9 \times$ 奥利亚罗非鱼 $\mathrm{a}$ 杂交所产后代奥尼鱼 由于其具有较高的雄性率、生长速度快、抗病力强、 抗寒及耐低氧能力强等优点 ${ }^{[3]}$, 深受各地养殖户的欢 迎，尤其在近几年频繁发生的罗非鱼链球菌病害中表 现出的较强抗病性, 更是得到了养殖户的认可。进一 步了解和掌握其双亲繁育群体的种质资源状况以及遗 传多样性水平等遗传资源信息的现状, 既有利于两种 罗非鱼群体的进一步选育, 也有利于奥尼罗非鱼品质 的完善和提高。因此对尼罗罗非鱼和奥利亚罗非鱼繁 殖群体的遗传潜力进行综合评价已显得尤为重要, 对 奥尼罗非鱼苗种品质的提高将会有一定帮助。

微卫星 DNA 由于具有在基因组中分布广泛、多 态性丰富、易于检测、进化所受选择压力小等特点, 在度量遗传多样性及构建系统发生树等研究中显示 出巨大的优势, 被认为是各类遗传标记中最有价值 的一种 ${ }^{[4 \sim 6]}$ 。国外已有对罗非鱼微卫星的研究, Kocher 等 ${ }^{[7]} 1998$ 年发表了尼罗罗非鱼的第一代遗传连锁 图谱, 其中分离了 112 个 AFLP 位点和 62 个微卫星位 点, 这些位点分布在罗非鱼 22 条染色体的 30 个连锁 群内。Lee 等 ${ }^{[8]} 2005$ 年发表了尼罗罗非鱼第二代遗传 连锁图谱, 报道了 525 个微卫星位点。在国内也有学 者运用微卫星标记技术对罗非鱼进行过遗传多样性分 析 ${ }^{[911]}$ ，但却未见利用微卫星标记对罗非鱼的遗传潜 力进行分析、归纳和总结的文章。本文利用 25 对微卫 星标记对来自两个地区的 2 个奥利亚罗非鱼群体和 4 个尼罗罗非鱼繁殖群体的遗传潜力进行分析。

\section{1 材料和方法}

\section{1 样本}

于 2008 年 6 月, 分别采集 6 个群体 2 龄鱼的血
液样本，具体信息见表 1 。取得的血样与 $\mathrm{ACD}$ 抗凝 剂(5:1)充分混合, $-70^{\circ} \mathrm{C}$ 保存备用。

表 16 个罗非鱼群体样本信息

\begin{tabular}{|c|c|c|c|}
\hline 群体名称 & \multicolumn{2}{|c|}{ 群体代号 样本量 } & 采集地点 \\
\hline 尼罗罗非鱼埃及品系 & $\mathrm{ZN}$ & 24 & 淡水渔业 \\
\hline 尼罗罗非鱼 88 品系 & XN & 30 & 淡水渔止 \\
\hline “夏奥 1 号” 奥利亚罗非鱼 & $\mathrm{ZA}$ & 30 & 淡水渔业研 \\
\hline 尼罗罗非鱼广西群体 & GN & 30 & 广西水产研究所 \\
\hline 尼罗罗非鱼美国品系 & $\mathrm{MN}$ & 30 & 广西水产研究所 \\
\hline 奥利亚罗非鱼广西群体 & GA & 30 & 广西水产研究所 \\
\hline
\end{tabular}

注: ZN 品系为 1992 年淡水渔业研究中心从埃及引进的尼罗罗非鱼, 经数代扩繁选育至今; XN 品系为 1988 年湖南湘湖渔场从埃及引进 的尼罗罗非鱼, 经淡水渔业研究中心转引并扩繁选育至今; ZA 品系 为淡水渔业研究中心 1983 年从美国引进的奥利亚罗非鱼, 经数代扩 繁选育后于 2006 年通过全国原种良种委员会审定通过定名为“夏奥 1 号”奥利亚罗非鱼; GN 群体为广西水产研究所于 2002 年从淡水渔 业研究中心引进的 ZN 群体, 经多代选育后形成的繁殖群体; MN 品 系为 1992 年淡水渔业研究中心引自美国奥本大学, 广西水产研究所 于 2004 年转引的群体; GA 群体为广西水产研究所于 2002 年从淡水 渔业研究中心转引的 ZA 原群体, 经多代选育后形成的繁殖群体。

\section{2 方法}

\subsection{1 基因组 DNA 的制备}

基因组 DNA 的提取方法见文献[12]，经琼脂糖 凝胶电泳和紫外分光光度计双重检测其浓度和纯度, 稀释成 $100 \mathrm{ng} / \mu \mathrm{L}$ 浓度作为 PCR 扩增的模板。

\section{2 .2 微卫星引物的设计}

本研究所用微卫星引物都是从已发表的尼罗罗 非鱼遗传连锁图谱中选取 ${ }^{[8]}$, 选取时尽量使这些引 物分布在各个连锁群内。选取具有多态性的 25 个微 卫星基因座进行遗传背景分析, 25 对引物的相关信 息见表 2。引物由上海捷瑞生物工程有限公司合成。

\subsubsection{PCR 扩增及检测}

篮选出的微卫星引物对群体进行 PCR 扩增, 扩增 反应全部在 Eppondorf Mastercycler gradient PCR 仪上 完成。反应体系: $10 \times \mathrm{PCR}$ 混合缓冲液 $2.5 \mu \mathrm{L}$, 微卫星 上下游引物 $(10 \mu \mathrm{mol} / \mathrm{L})$ 各 $1 \mu \mathrm{L}, \operatorname{dNTPs}(2.5 \mathrm{mmol} / \mathrm{L})$ $2.5 \mu \mathrm{L}, \mathrm{Taq}$ DNA 聚合酶(宝生物工程(大连)有限公 司) $1 \mathrm{U}, \mathrm{DNA}$ 模板 $(100 \mathrm{ng} / \mu \mathrm{L}) 1 \mu \mathrm{L}$, 补无菌去离子 水至 $25 \mu \mathrm{L}$ 。反应程序: $95^{\circ} \mathrm{C}$ 变性 $4 \mathrm{~min} ; 94^{\circ} \mathrm{C}$ 变性 $30 \mathrm{~s}$, 各引物 $54 \sim 60^{\circ} \mathrm{C}$ 复性 $30 \mathrm{~s}, 72^{\circ} \mathrm{C}$ 延伸 $1 \mathrm{~min}, 28$ 个循环；最后 $72^{\circ} \mathrm{C}$ 延伸 $10 \mathrm{~min}$ 。 


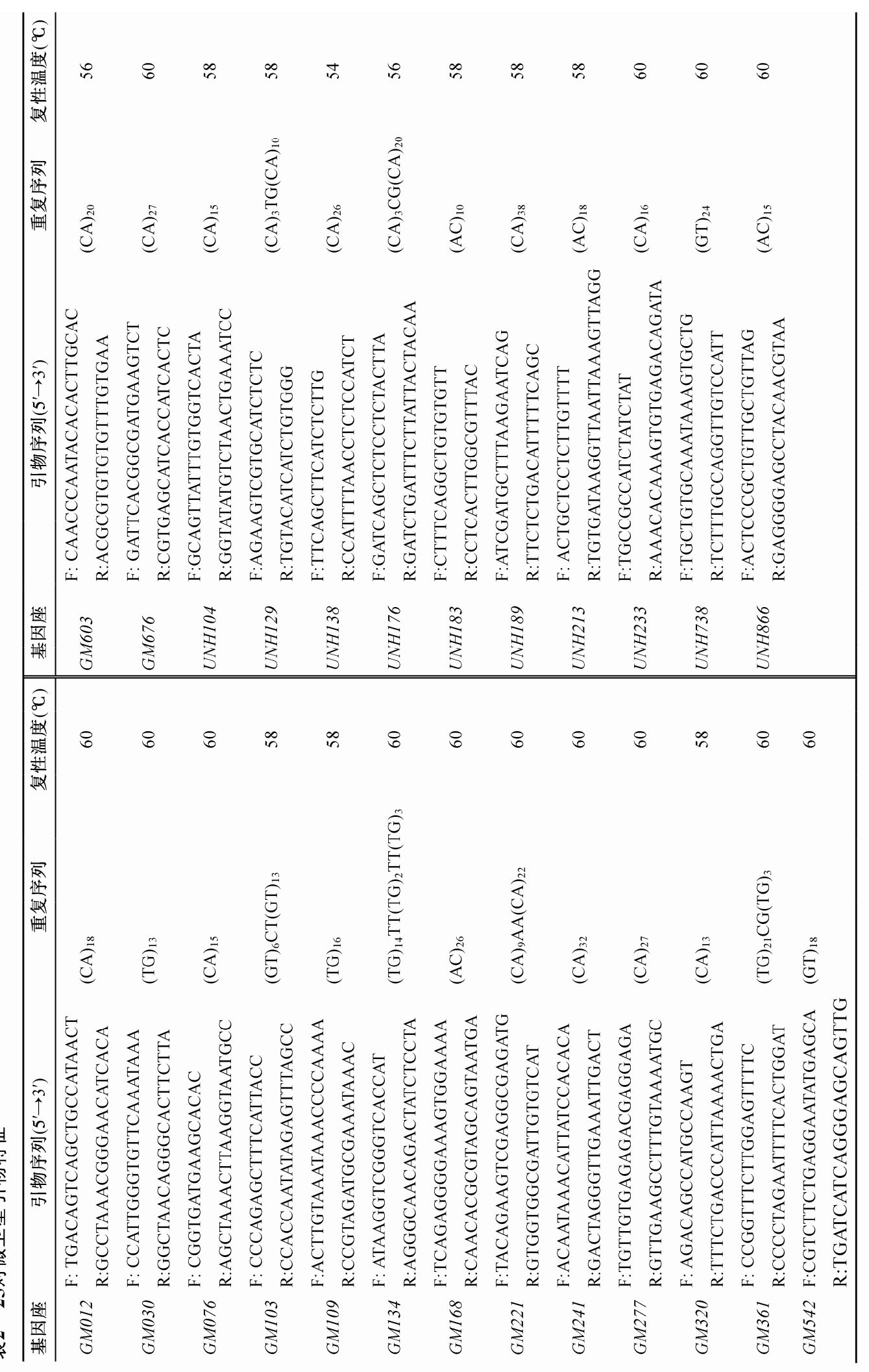


PCR 扩增反应产物用 $8 \%$ 聚丙烯酰胺凝胶电泳 检测，BIO-RAD PowerPac Universal 电泳仪 $5 \mathrm{~V} / \mathrm{cm}$ 电泳 $4 \mathrm{~h}$ 左右, GelRed 染色, G:box 凝胶成像系统 (Gene Company Limited)记录电泳结果, Gel-Pro Analyzer 软件(Version 4.5)分析扩增条带的分子量差异。

\section{2 .4 数据分析}

使用 PopGene 1.32 软件计算每个群体的等位基 因数(Observed number of alleles, $N_{a}$ )、有效等位基因 数 (Effective number of alleles, $A_{e}$ )、观测杂合度 (Observed heterozygosity, $H_{o}$ )、期望杂合度(Expected heterozygosity, $\left.H_{e}\right)$ 、群体间近交系数 $\left(F_{s t}\right)$ 和基因流 $\left(N_{m}\right)$, 遗传相似系数(Genetic similarity index, $\left.I\right)$, 群 体间遗传距离 (Genetic distance, $D_{s}$ )。同时利用软件 Genepop3.4 的 $P$ 值对各位点进行 Hardy-Weinberg 平 衡检测。利用 ARLEQIUN 3.1 软件进行分子方差分 析(AMOVA)。Botstein 等 ${ }^{[13]}$ 计算多态信息含量 $(P I C)$ :

$$
P I C=1-\left(\sum_{i=1}^{n} P_{i}^{2}\right)-\left(\sum_{i=1}^{n-1} \sum_{j=i+1}^{n} 2 P_{i}^{2} P_{j}^{2}\right)
$$

其中, $n$ 为某一位点上等位基因数, $P_{i} 、 P_{j}$ 分别为第 $i$ 和第 $j$ 个等位基因在群体中的频率, $j=i+1$ 。

根据群体间遗传距离, 用 MEGA3 UPGMA (Unweighted Pair Group Method with Arithmetic means, 类平均法)绘制聚类图, 并利用 Bootstrap test 检验所 得聚类结果的可靠性。

\section{2 结果与分析}

\section{1 微卫星位点的篮选和扩增结果}

本实验中的 25 对引物能在 6 个罗非鱼群体中同 时得到清晰且重复性较好的产物。2 5 对引物在 6 个 群体中共扩增出 7775 个条带, 扩增片段大小范围 在 131 408 bp 之间。其中引物 GM168、GM361、 GM183 在奥利亚罗非鱼广西群体(GA)中扩增出单 态，引物 GM030、GM361、GM183、UNH213 在“夏
奥 1 号” 奥利亚罗非鱼 $(\mathrm{ZA})$ 群体中扩增出单态, 引物 GM603 在尼罗罗非鱼 88 品系 $(\mathrm{XN})$ 中扩增出单态, 其 他引物在各群体中均扩增出不同程度的多态性条带。

\section{2 群体遗传参数分析}

25 对微卫星引物在 6 个罗非鱼群体中共检测到 了 143 个等位基因，大多集中在 100 300 bp 之间。 不同基因座位上的等位基因数在 3 8 个之间, 其中 GM211、GM277、UNH1383 个基因座上的等位基因 数最多为 8 个, 表现出高度的多态性; 而 GM030 基 因座上的等位基因数最低仅 3 个, 平均每个基因座 上的等位基因数为 5.72 个。就 4 个遗传参数(表 3) 而言，6 个罗非鱼群体间遗传变异差别不大: (1) 平 均有效等位基因数 $(\overline{A e})$ 在 2.20 3.23 之间，尼罗罗非 鱼群体的等位基因数均比奥利亚群体的等位基因数 多，各群体所有基因座所有等位基因数统计结果显 示尼罗罗非鱼美国品系(MN)的等位基因数最多(100 个), “夏奥 1 号” 奥利亚罗非鱼(ZA)最少(66 个)。 (2) 平均多态信息含量 $(\overline{P I C})$ 奥利亚罗非鱼两个群体 的 PIC 相对较低( $0.4212 、 0.4626)$, 尼罗罗非鱼 4 个 群体的 $P I C$ 除尼罗罗非鱼埃及品系 $(\mathrm{ZN})$ 低于 0.5 之 外, 其他 3 个群体均高于 0.5。(3) 平均观测杂合度 $\left(\overline{H_{o}}\right)$ 在 $0.7253 \sim 0.8160$ 间, 尼罗罗非鱼广西群体 $(\mathrm{GN})$ 最高, “夏奥 1 号” 奥利亚罗非鱼 $(Z A)$ 群体最低。(4) 平均期望杂合度 $(\overline{H e})$ 在 $0.5146 \sim 0.6834$ 之间。

\subsection{Hardy-Weinberg 平衡估算}

用基于马可夫链模型(Markov chain method)的 Hardy-Weinberg 精确 $P$ 值的无偏估测对各群体的多 基因座检测(Multi-1ocus test), 认为 6 个罗非鱼群体 都处于遗传平衡状态; 而对各基因座进行的多群体 检测(Multi-group test)则发现，有 4 个基因座出现了 显著的遗传不平衡性; 单群体单基因座检测( $\mathrm{HW}$ test for each locus in each population)表明, 6 个群体

表 36 个罗非鱼群体在 25 个微卫星座位的遗传参数

\begin{tabular}{lcccccc}
\hline \multicolumn{1}{c}{ 种群 } & $\mathrm{ZN}$ & $\mathrm{GN}$ & $\mathrm{ZA}$ & $\mathrm{GA}$ & $\mathrm{MN}$ & 3.23 \\
\hline 平均有效等位基因数 $\overline{A e}$ & 2.46 & 2.99 & 2.20 & 2.43 & 0.76 \\
平均多态信息含量 $\overline{P I C}$ & 0.4864 & 0.5827 & 0.4212 & 0.4626 & 0.5417 \\
平均观测杂合度 $\overline{H o}$ & 0.7867 & 0.8160 & 0.7253 & 0.7587 & 0.7853 & 0.7720 \\
平均期望杂合度 $\overline{H e}$ & 0.5811 & 0.6572 & 0.5146 & 0.6834 & 0.6229 \\
\hline
\end{tabular}


表 46 个罗非鱼群体遗传平衡分析

\begin{tabular}{|c|c|c|c|c|c|c|c|}
\hline \multirow{2}{*}{ 基因座 } & \multicolumn{6}{|c|}{ 单群体检测 } & \multirow{2}{*}{ 多群体检测 } \\
\hline & $\mathrm{ZN}$ & GN & $\mathrm{ZA}$ & GA & $\mathrm{XN}$ & $\mathrm{MN}$ & \\
\hline GM012 & 0.3674 & 0.5488 & 0.0003 & 0.9637 & 0.0104 & 0.3869 & 0.0259 \\
\hline GM030 & 1 & 1 & 1 & 1 & 1 & 1 & 1 \\
\hline GM076 & 0.9981 & 1 & 1 & 0.9915 & 0.9962 & 0.9862 & 1 \\
\hline GM103 & 1 & 1 & 0.9996 & 1 & 0.0609 & 0.1697 & 1 \\
\hline GM109 & 0.2279 & 0.0000 & 0.2838 & 0.1547 & 0.2234 & 0.0180 & 0.0000 \\
\hline GM134 & 0.7908 & 0.0003 & 0.3986 & 0.0121 & 0.4238 & 0.0000 & 0.0000 \\
\hline GM168 & 0.8410 & 1 & 1 & 1 & 0.2375 & 0.9964 & 1 \\
\hline GM221 & 0.5285 & 0.8000 & 1 & 1 & 1 & 0.9671 & 1 \\
\hline GM241 & 1 & 1 & 0.8258 & 0.8670 & 0.4996 & 0.6944 & 0.9999 \\
\hline GM277 & 0.9998 & 1 & 1 & 1 & 0.9999 & 0.6521 & 1 \\
\hline GM320 & 1 & 1 & 1 & 1 & 1 & 1 & 1 \\
\hline GM361 & 0.9828 & 0.9978 & 1 & 1 & 1 & 0.9993 & 1 \\
\hline GM542 & 0.9996 & 0.9987 & 1 & 0.9998 & 1 & 1 & 1 \\
\hline GM603 & 0.8474 & 0.7734 & 0.0188 & 0.4389 & 0.9837 & 0.0015 & 0.1150 \\
\hline GM676 & 0.9945 & 0.9938 & 1 & 0.5852 & 1 & 0.8425 & 1 \\
\hline NH104 & 1 & 0.8651 & 1 & 1 & 0.3749 & 1 & 1 \\
\hline NH129 & 1 & 0.8304 & 0.5988 & 0.9909 & 0.9946 & 0.9993 & 1 \\
\hline NH138 & 1 & 0.8389 & 1 & 1 & 1 & 0.9882 & 1 \\
\hline NH176 & 1 & 1 & 1 & 1 & 0.9920 & 0.6583 & 1 \\
\hline NH183 & 0.1518 & 0.0004 & - & - & 0.0000 & 0.0000 & 0.0000 \\
\hline NH189 & 0.9978 & 0.9910 & 1 & 1 & 0.9970 & 1 & 1 \\
\hline $\mathrm{NH} 213$ & 0.8990 & 0.9826 & - & 1 & 0.9879 & 0.9933 & 1 \\
\hline NH233 & 0.9939 & 1 & 0.9983 & 0.9933 & 0.9981 & 0.9959 & 1 \\
\hline NH738 & 1 & 1 & 1 & 1 & 1 & 1 & 1 \\
\hline NH866 & 1 & 1 & 1 & 1 & 0.9991 & 1 & 1 \\
\hline 基因座检测 & 1 & 1 & 1 & 1 & 1 & 1 & 1 \\
\hline
\end{tabular}

中有 $2.67 \%$ 的基因座表现为显著的遗传不平衡 $(0.01<$ $P<0.05), 5.41 \%$ 的基因座表现为极显著的遗传不平 衡 $(P<0.01)$, 其余 $91.89 \%$ 的基因座处于遗传平衡 状态 $(P>0.05$, 表 4$)$ 。

\section{4 群体间遗传变异及亲缘关系}

用配子间相关系数或称近交系数 $\left(F_{s t}\right)$ 与基因流 $\left(N_{m}\right)$ 分析 6 个群体间的遗传分化情况, 2 个奥利亚罗 非鱼群体在 25 个基因座中有 19 个基因座(76\%)的近 交系数处在群体间无遗传分化的标准范围内 $\left(F_{s t}=0 \sim\right.$ $0.05)^{[14]}$, 各基因座的近交系数的均值为 0.0423 , 基 因流的均值为 $5.6659 ; 4$ 个尼罗罗非鱼群体在 25 个 基因座上有 23 个基因座(92\%)的近交系数大于群体 间无遗传分化标准, 各基因座的近交系数的均值为 0.1370 ，基因流的均值为 1.5744 。

使用 ARLEQIUN 3.1 软件计算 6 个群体之间的
遗传分化指数 $\left(F_{s t}\right)$ 在 0.0599 0.3447 之间(表 5), 遗传 分化最大的是尼罗罗非鱼埃及品系和“夏奥 1 号” 奥利亚罗非鱼, 2 个奥利亚罗非鱼群体遗传分化最 小。分子方差分析(AMOVA)结果表明, 群体间方差 占总方差的 $20.15 \%$, 而群体内方差占总方差的 $79.85 \%$ ，对尼罗罗非鱼和奥利亚罗非鱼各群体之间 变异方差来源(表 6)的进一步分析表明, 各群体的遗 传变异大部分来源于群体内个体间的遗传变异。

6 个罗非鱼群体间的 Nei's 遗传距离 $\left(D_{s}\right)$ 和遗传 相似系数 $(I)$ 的计算(表 6)表明, $D_{s}$ 和 $I$ 分别在 $0.0911 \sim$ $0.8319 、 0.4352 \sim 0.9130$ 之间。根据 $D_{s}$ 值采用 UPGMA 法构建的系统发生树(图 1)表明, 2 个奥利亚罗非鱼 群体为第 1 支, 尼罗罗非鱼埃及品系 $(\mathrm{ZN})$ 和尼罗罗 非鱼广西群体 $(\mathrm{GN})$ 为第 2 支, 尼罗罗非鱼美国品系 $(\mathrm{MN})$ 和尼罗罗非鱼 88 品系 $(\mathrm{XN})$ 聚为第 3 支, 第 1 支系与第 2 支系关系较远。 
表 56 个罗非鱼群体间遗传相似系数(上三角)、奈氏遗传距离(下三角括号外)及群体间 $\boldsymbol{F}_{s t}$ 值 $($ 下三角括号内)

\begin{tabular}{ccccccc}
\hline 群体 & ZN & GA & GN & ZA & MN & XN \\
\hline ZN & - & 0.4636 & 0.8259 & 0.4352 & 0.6441 & 0.5520 \\
GA & $0.7687(0.2953)$ & - & 0.5727 & 0.9130 & 0.4479 & 0.5919 \\
GN & $0.1913(0.0904)$ & $0.5575(0.2206)$ & - & 0.5621 & 0.6586 & 0.6021 \\
ZA & $0.8319(0.3447)$ & $0.0911(0.0599)$ & $0.5760(0.2560)$ & - & 0.4517 & 0.5566 \\
MN & $0.4399(0.1283)$ & $0.8032(0.2509)$ & $0.4176(0.0726)$ & $0.7948(0.2752)$ & - & 0.6765 \\
XN & $0.5942(0.1633)$ & $0.5244(0.2382)$ & $0.5074(0.1309)$ & $0.5858(0.2761)$ & $0.3908(0.1572)$ & - \\
\hline
\end{tabular}

表 66 个罗非鱼群体的 AMOVA 分析

\begin{tabular}{lcccc}
\hline \multicolumn{1}{c}{ 变异来源 } & 自由度 方差总和 & 变异组分 & $\begin{array}{c}\text { 所占比例 } \\
(\%)\end{array}$ \\
\hline 奥利亚罗非鱼群体间 & 1 & 24.942 & $0.33863 \mathrm{Va}$ & 6.82 \\
奥利亚罗非鱼群体内 & 118 & 545.617 & $4.62387 \mathrm{Vb}$ & 93.18 \\
尼罗罗非鱼群体间 & 3 & 180.623 & $0.94836 \mathrm{Va}$ & 13.08 \\
尼罗罗非鱼群体内 & 224 & 1411.333 & $6.30060 \mathrm{Vb}$ & 86.92 \\
所有群体间 & 5 & 450.575 & $1.45597 \mathrm{Va}$ & 20.15 \\
所有群体内 & 342 & 1973.083 & $5.76925 \mathrm{Vb}$ & 79.85 \\
\hline
\end{tabular}

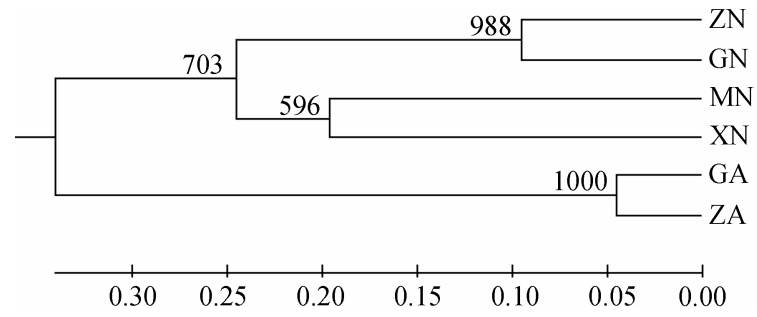

图 1 基于 Nei's 氏标准遗传距离 $\left(D_{s}\right)$ 值的 6 个罗非鱼群体 的 UPGMA 聚类图

\section{3 讨 论}

\section{1 罗非鱼的遗传潜力}

$A_{e} 、 H_{o} 、 H_{e} 、 P I C$ 等遗传参数可以从多个角度 反映群体的遗传多样性和遗传潜力, 各参数在一定 范围内其数值越高, 说明该群体的基因丰富程度越 高, 其遗传多样性也越高, 遗传潜力也越大, 对其 群体进行种质资源挖掘和选育的潜力也就越大; 反 之则遗传潜力越低, 选育的可行性也越低(但并非不 可行)。从本研究的结果来看, 6 个群体的 PIC 均值为 0.5175 , 其中尼罗罗非鱼美国品系(MN)群体最高 (0.6105), “夏奥 1 号” 奥利亚罗非鱼 $(Z A)$ 最低(0.4212)。 依据 Botstein 提出的判别群体遗传多样性高低的标 准 $^{[13]}$, 本实验中尼罗罗非鱼美国品系、广西群体及 88 品系属高度遗传多样性水平, 尼罗罗非鱼埃及品 系 $(\mathrm{ZN})$ 以及奥利亚罗非鱼 2 个群体 $(\mathrm{GA} 、 \mathrm{ZA})$ 为中度
偏高的遗传多样性水平。袁文华等 ${ }^{[15]}$ 利用 8 对微卫 星引物对奥尼鱼及其亲本遗传多样性分析得出奥利 亚罗非鱼和尼罗罗非鱼的 PIC 分别为 $0.4133 、 0.4693$; 蒋家金等 ${ }^{[10]}$ 采用微卫星标记分析了尼罗罗非鱼、吉 富罗非鱼的 2 个品系及奥利亚罗非鱼群体, 其 PIC 分别为 $0.4127 、 0.4195 、 0.3927$ 和 0.3592 , 他们的测 定值均低于本研究, 可能是由于本研究中 6 个罗非 鱼群体仍然保持着较高的遗传多样性水平。

从 $A_{e} 、 H_{o} 、 H_{e}$ 几个参考值角度来看, 本研究中 2 个奥利亚罗非鱼群体的 $\overline{A e}(2.315) 、 \overline{H_{o}}(0.7420)$ 、 $\overline{H_{e}}(0.5294)$ 均高于张庭等 ${ }^{[9]}$ 分析 4 个奥利亚罗非鱼 群体 $\left(\overline{A_{e}}=1.62 、 \overline{H_{o}}=0.2530 、 \overline{H_{e}}=0.3140\right)$ 的结果; 4 个尼罗罗非鱼群体的 $\overline{A e}(2.86) 、 \overline{H_{o}}(0.7900) 、 \overline{H_{e}}$ (0.6362)均略低于李先仁等 ${ }^{[11]}$ 分析 8 个尼罗罗非鱼 群体 $\left(\overline{A_{e}}=3.33 、 \overline{H_{o}}=0.8877 、 \overline{H_{e}}=0.6581\right)$ 的结果。 但一致的是, 奥利亚罗非鱼的各项遗传参数均明显 低于尼罗罗非鱼。这同中国国内的奥利亚罗非鱼的 来源较为单纯、群体遗传纯度高 ${ }^{[16]}$ 有关。遗传多样 性的降低非常不利于其群体的发展和进化, 但对于 养殖鱼类来说, 遗传多样性降低意味着群体内变异 较小、个体间同一性较高、遗传性状较稳定, 这对 于养殖鱼类的繁殖群体来说则具有重要意义 ${ }^{[17]}$ 。较 高的遗传纯度有利于杂种优势的提高和杂交子代性 状的稳定, 但对于纯种的保存和复壮是不利的。本 研究中 2 个奥利亚罗非鱼群体是中国引进奥利亚罗 非鱼的原始引种群体的后代群体, 其各项遗传参数 均高于其他学者研究得到的其他育种单位再引群体 的参数值, 证明此 2 群体的种质保存工作是比较成 功的, 较大程度地保护了奥利亚罗非鱼群体的遗传 多样性水平, 其遗传潜力相对来讲还是较高的, 有 继续对其进行新品种选育和种质资源挖掘可能性。 中国国内的尼罗罗非鱼由于引种频繁、来源较 
$广^{[18]}$, 其遗传背景较为复杂, 各品种或群体引入国 内时其奠基群体相对较大, 遗传瓶颈效应并不明显, 所以从目前各学者的研究结果来看, 其遗传多样性 水平均高于奥利亚罗非鱼。遗传多样性水平较高, 遗传潜力就相应的较高, 这对于种质资源的保存以 及新品种的选育十分有利, 但如果遗传多样性过高, 在运用传统手法如系统选育法、群体选育法等手段 进行新品种选育时就要经历更多世代的人工选择和 性状提纯，不利于新品种的快速选育和优良性状的 稳定。本研究中 4 个尼罗罗非鱼群体遗传多样性水 平较高、遗传潜力大, 对其进行进一步的种质资源 挖掘、选育新品种的潜力很大。

\section{2 遗传平衡和遗传变异}

遗传平衡定律阐述了群体中基因频率和基因型 频率的本质关系, 是揭示生物群体保持遗传稳定性 的理论基础, 其最大应用是为了解群体遗传结构提 供方便 ${ }^{[19]}$ 。本研究利用 Hardy-Weinberg 无偏估测对 各群体进行多基因座检测, 结果(表 4)显示 6 个罗非鱼 群体都处于遗传平衡状态; 而对各基因座进行的多群 体检测(表 4)则显示有 1 个基因座出现了显著的遗传不 平衡, 3 个基因座出现了极显著的遗传不平衡; 单群体 单基因座检测(表 4)发现 6 个群体中有 $2.70 \%$ 的基因座 表现为显著的遗传不平衡, $5.41 \%$ 的基因座表现为极 显著的遗传不平衡, 其余 $91.89 \%$ 的基因座是处于遗 传平衡状态。简单来讲, 该结果说明单群体多基因座 检测时每个群体都是处于遗传平衡状态的, 但单基因 座单个群体检测时发现有 $8.11 \%$ 的基因座出现不同程 度的遗传不平衡。单群体多基因座检测结果遗传平衡 可以说明每个罗非鱼群体内各个个体间是始终保持着 随机交配的, 即使由于各种因素改变了群体的基因频 率和基因型频率, 只要能保持随机交配, 这个群体仍 将保持遗传平衡 ${ }^{[19]}$ 。单基因座多群体检测结果有个别 基因座不平衡说明各群体之间在该基因座上已经出现 了一定程度的分化, 但总体来讲, 不平衡的基因座仍 属少数, 不影响总体的遗传平衡。单群体单基因座检 测结果说明绝大部分基因座处于平衡状态, 但仍有少 部分基因座出现了不同程度的不平衡，这对于选择后 的群体来说是正常的, 只要各群体容量足够大并且能 保持随机交配，最终仍会达到遗传平衡状态。

地理隔离、生存环境、种群瓶颈、基因流、选
择等因素对种群遗传结构的影响都是很大的, 遗传 变异是适应不断变化的生存环境所必需的。对于作 为引进种的罗非鱼来说, 在各个地方群体遗传研究 中常可以发现群体的遗传隔离和潜在种的分化。在 本研究中两个奥利亚罗非鱼群体之间近交系数的均 值为 0.0423 , 根据公式 $N_{m}=\left(1-F_{s t}\right) / 4 F_{s t}$, 计算出群 体间基因流的均值为 5.6659, 4 个尼罗罗非鱼群体近 交系数的均值为 0.1370 ，基因流的均值为 1.5744 。 有学者认为, $N_{m}>1$ 时, 就可以阻止由遗传漂变而引 起的种群间的分化; 理论上 $N_{m}<1$ 时, 遗传漂变是 群体间遗传分化的主要因素; $N_{m}>1$ 时, 基因流为主 要作用 ${ }^{[20]}$ 。运用 ARLEQIUN3.1 软件进一步计算各 个群体之间的遗传分化指数 $\left(F_{s t}\right)$ 在 $0.0599 \sim 0.3447$ 之间变动, 而且群体两两间差异均达显著水平 $(P<$ $0.05)$ 。依据 Wright ${ }^{[14]}$ 提出标准可以看出, 本研究中 两个奥利亚罗非鱼群体遗传分化不明显, 奥利亚罗 非鱼群体和各尼罗罗非鱼群体之间遗传分化较大, 各尼罗罗非鱼群体之间呈中等程度的遗传分化。

Shaklee 等 ${ }^{[21]}$ 综合已发表的资料，提出鱼类在 属、种和种群三级水平上的遗传距离 $D_{s}$ 平均值分别 为 $0.90 、 0.30$ 及 0.05 的分类依据。在本研究中, 2 个 奥利亚罗非鱼群体间的遗传距离为 0.0911 , 略大于 种群分类标准 $(0.05 \sim 0.3)$, 可划为同种不同群体; 4 个 尼罗罗非鱼群体彼此间遗传距离平均值为 0.4235 , 略大于种的分类标准(0.3 0.9)，4 者间已出现种的分 化, 这可能与尼罗罗非鱼各群体的来源较为复杂以 及经历过多代选育有直接关系; 奥利亚罗非鱼与尼 罗罗非鱼群体间平均遗传距离为 0.6803 , 符合不同 种间的分类标准( $0.3 \sim 0.9)$ 。遗传距离是研究物种遗传 多样性的基础，一般认为群体分化时间越短，遗传 距离越小。Crawford 等 ${ }^{[22]}$ 指出由微卫星得出的遗传 距离更能反映分化时间的长短, 能客观地反映品种 间的遗传变异和分化, 这也体现在 6 个群体以遗传 距离 $\left(D_{s}\right)$ 构建的聚类图上(图 1)。现代杂种优势理论 认为杂种优势的大小在一定程度上取决于亲本间遗 传差异的大小，遗传距离愈大所产生的杂种优势愈 大。用 DNA 多态性预测杂种优势比较准确, 其中由 微卫星计算所得的遗传距离还可用于预测杂交组合 的优劣性，使实际杂交实验避免盲目性 ${ }^{[23]}$ 。

通过分子方差分析对变异来源的剖分(表 6)表 明，群体间变异占总变异的 $20.15 \%$, 其中奥利亚罗 
非鱼群体间的遗传变异占奥利亚罗非鱼所有变异的 $6.82 \%$, 尼罗罗非鱼群体间变异占尼罗所有变异的 $13.08 \%$ 。群体的遗传变异大部分来源于各群体内个 体间的遗传变异, 表明选育过程中近交及瓶颈效应 发生的可能性不大, 群体遗传结构的改变主要是由 人工选择压力造成的。

\section{3 罗非鱼遗传潜力的维持}

为了更大程度地保持罗非鱼群体的遗传潜力, 保 持其种群大小在有效群体容量之上显得尤为重要。 Taniguchi ${ }^{[24]}$ 提出 $N_{e}=50$ 对于大多数鱼类群体来讲是最 小的群体容量, $N_{e}=\left[H_{e} /\left(1-H_{e}\right)\right] / 4 \mu^{[25]}$, 式中 $\mu$ 为微卫星

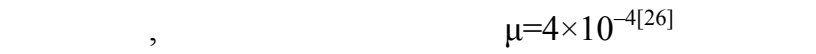
算, 各群体比较合适的有效群体容量依次为尼罗罗非 鱼美国品系 1349 尾、尼罗罗非鱼广西群体 1198 尾、 尼罗罗非鱼 88 品系 1032 尾、尼罗罗非鱼埃及品系 867 尾、奥利亚罗非鱼广西群体 746 尾、“夏奥 1 号” 奥利 亚罗非鱼 663 尾, 就我国目前情况来看, 该 6 个罗非鱼 群体实际群体大小均远大于 Taniguchit 提出的指标(尼 罗罗非鱼美国品系实际大小为 5800 尾、尼罗罗非鱼 广西群体实际大小为 6484 尾、尼罗罗非鱼 88 品系 2 463 尾、尼罗罗非鱼埃及品系 2257 尾、奥利亚罗非鱼 广西群体 6250 尾、“夏奥 1 号” 奥利亚罗非鱼 1486 尾), 足以保证有效群体容量大小, 对有效保护和持续 利用罗非鱼遗传潜力极为有利。

\section{参考文献(References):}

[1] 夏德全. 中国罗非鱼养殖现状及发展前景. 科学养鱼, 2000, (5): 1-1, 21 .

[2] 崔和. 中国罗非鱼产业现状. 海洋与渔业, 2008, (1): 3-5.

[3] 王楚松, 夏德全, 胡玫, 王和海. 奥尼鱼 $(O$. nilotica $9 \times O$.

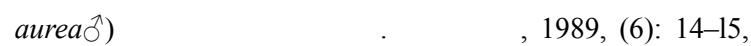
13.

[4] 张云武, 张亚平. 微卫星及其应用. 动物学研究, 2001, 22(4): $315-320$

[5] 曹君, 霍雅鹏, 杜杨, 张宇婷, 万冬梅. 微卫星 DNA 在亲 权关系鉴定中的应用. 辽宁大学学报(自然科学版), 2010, 37(2): $156-159$.

[6] 盛岩, 郑蔚虹, 裴克全, 马克平. 微卫星标记在种群生物 学研究中的应用. 植物生态学报, 2002, 26(增刊): 119-126.

[7] Kocher TD, Lee WJ, Sobolewska H, Penman D, McAndrew B. A genetic linkage map of a cichlid fish, the tilapia (Oreochromis niloticus). Genetics, 1998, 148(3): 1225-1232.

[8] Lee BY, Lee WJ, stree1man JT, Carleton KL, Howe AE, Hu- lata G, Slettan A, Stern JE, Terai Y, Kocher TD. A second-generation genetic linkage map of tilapia (Oreochromis spp.). Genetics, 2005, 170(1): 237-244.

[9] 张庭, 卢迈新, 叶星, 全迎春, 高风英, 黄樟翰, 白俊杰. 四个奥利亚罗非鱼群体的微卫星分析. 水生生物学报, 2009, 33(3): 498-508

[10] 蒋家金, 李瑞伟, 叶福良. 罗非鱼 4 个选育群体遗传结构 SSR 分析. 广东海洋大学学报, 2008, 28(4): 10-14.

[11] 李先仁, 李思发, 唐首杰, 蔡完其. 尼罗罗非鱼 8 个养殖群 体遗传差异的微卫星分析. 上海海洋大学学报, 2009 , 18(1): 1-7.

[12] Sambrook J, Russell DW. Molecular Cloning: A Laboratory Manual, 3rd ed. Beijing: Science Press, 2002.

[13] Botstein D, White RL, Skolnick M, Davis RW. Construction of a genetic linkage map in man using restriction fragment length polymorphisms. Am J Human Genet, 1980, 32(3): 314-331.

[14] Wright S. Evolution and the genetics of populations. Chicago: University of Chicago Press, 1978.

[15] 袁文华, 刘丽, 刘楚吾, 谭围. 奥尼罗非鱼及其亲本的微 卫星分析. 现代农业科学, 2009, 16(6): 27-30, 47.

[16] 王进科, 夏德全, 吴婷婷. 中国奠基群奥利亚罗非鱼遗传 多态性的 DNA 指纹图谱. 南京农业大学学报, 2000, 23(3): 61-63.

[17] 李大宇，殷倩茜，侯宁，孙效文，梁利群。黄颡鱼 (Pelteobagrus eupogon)不同生态地理分布群体遗传多样性 的微卫星分析. 海洋与湖沼, 2009, 40(4): 460-469.

[18] 李家乐, 李思发. 中国大陆尼罗罗非鱼引进及其研究进展. 水产学报, 2001, 25(1): 90-95.

[19] 苏从成, 张海容. 遗传平衡定律的推广形式及其应用. 畜 牧兽医杂志, 2009, 28(6): 24-26.

[20] Slatkin M. Gene flow and the geographic structure of natural populations. Science, 1987, 236(4803): 787-792.

[21] Shaklee JB, Tamaru CS, Waples RS. Speciation and evolution of marine fishes studied by the electrophoretic analysis of proteins. Pac Sci, 1982, 36(2): 141-157.

[22] Crawford AM, Littlepohn RP. The use of DNA markers in deciding conservation priorities in sheep and other livestock. Anim Genet Res Inf, 1998, 23(1): 21-26.

[23] 孙少华, 桑润滋, 师守㫃, 贾青, 李运起, 李雪梅, 田树军, 高聚山，问国志，丁玉臣，黄亚新. 肉牛杂交优势预测、评 估及其应用研究. 遗传学报, 2000, 27(7): 580-589.

[24] Taniguchi N. Genetic factors in broodstock management for seed production. Fish Biol Fisher, 2003, 13(2): 177-185.

[25] Kimura M, Crow JF. The number of alleles that can be maintained in a finite population. Genetics, 1964, 49(4): 725-738.

[26] García FJ, Chikhi L, Bonhomme F. Microsatellite polymorphism and population subdivision in natural populations of European sea bass, Dicentrarchus labrax (Linnaeus, 1758). Mol Ecol, 1997, 6(1): 51-62. 